\title{
Content analysis of vacancy advertisements for employability skills: Challenges and opportunities for informing curriculum development
}

\author{
Diana Messum ${ }^{1}$, Lesley Wilkes ${ }^{1}$, Kath Peters ${ }^{1} \&$ Debra Jackson ${ }^{2}$ \\ d.messum@uws.edu.au; I.wilkes@uws.edu.au; k.peters@uws.edu.au; \\ djackson@brookes.ac.uk \\ ${ }^{1}$ Western Sydney University, ${ }^{2}$ Oxford Brookes University, UK
}

\begin{abstract}
The process of curriculum development can be informed by seeking the views of stakeholders, including employers, academics, students and recent graduates, about the skills, attributes and personal characteristics required by various professions. The views of several stakeholders may also be compared to help ensure reliability of results and identify areas of agreement or variance. However, there are documented limitations regarding the perceptions of academics and students of employability skills, and also problems with employers' and recent graduates' views. Another approach to identifying the skills required in various professions is content analysis of job vacancy advertisements. Content analysis of advertisements is a versatile way of identifying current skills required by various professions, and allows comparison across countries and over time to identify trends. Yet there is little evidence to suggest that this information is used to inform curriculum development. This paper presents a qualitative integrative review of studies looking at employability skills (ES) through the use of content analysis of job vacancy advertisements. Here ES are equated with essential requirements stated in vacancy advertisements. ES is the term adopted in Australia by DEST (2002) to define skills required to both secure employment and progress in an organisation. The Critical Appraisal Skills Programme (2014) checklist for qualitative research was used in this integrative review of 40 studies. The range of application, research methods used and findings are discussed in this paper, as are the advantages and challenges associated with analysing job vacancy advertisements as a method of identifying employability skills (ES) required by employers.
\end{abstract}

Key words: employability skills, generic skills, content analysis, advertisements, job vacancies

\section{Introduction}

Adequately identifying the required skills of professions and industry is important in higher education institutions (HEIs) to ensure that curriculum remains relevant and current, thereby yielding high rates of graduate employment (a sector performance indicator) and attracting new students. The requirements of industry must first be clarified for employability capabilities to be embedded in the curriculum and to help ensure the work-readiness of graduates, consistent with the recent National WIL Strategy (Universities Australia, 2014). Furthermore, the contextual nature of employability skills (ES) has long been recognised (DEWR, 2012), which means that industry specific ES need to be identified. Although industry generally appears satisfied with the discipline-specific skills of graduates, there is ongoing evidence that ES are under-developed (Precision Consultancy, 2007; Graduate Careers Australia (GCA), 2015). While employer preferences for graduates who can 'hit the ground running' have been

Messum, D., Wilkes, L., Peters, K., \& Jackson, D. (2016). Content analysis of vacancy advertisements for employability skills: Challenges and opportunities for informing curriculum development. Journal of Teaching and Learning for Graduate 
reported (Ferns \& Lilly, 2015; Semeijn, Veldon, Heijke, Vlueten, \& Boshuizen, 2006; Ridoutt, Selby Smith, Hummel, \& Cheang, 2005), deficiencies in written and oral skills (GCA, 2015; CBI, 2013; Archer \& Davison, 2008) have been reported. GCA (2015) found deficiencies in self-management skills, planning/organising, initiative/enterprise and problem solving skills in their annual survey of a range of industries across Australia. Communication skills, teamwork and technology skills were rated better, but were still in need of improvement. In the UK, deficits in integrity, teamwork, problem solving, literacy, numeracy, critical analysis skills, planning, organising and self-management have also been reported by employers (Hinchliffe \& Jolly, 2014; Tymon, 2011). These generic ES seem more useful than job-specific skills for coping with rapidly changing and complex work environments such as in the health field (Liang, Short, \& Brown, 2006) and library information services (Harper, 2012). Although employee expectations for work readiness are also typically defined in terms of generic rather than discipline specific skills, with communication skills consistently emerging as the most important ES, it would appear that these are not being sufficiently demonstrated. In 2015, 23.4 per cent of Australian employers indicated that they had difficulty sourcing/recruiting graduates and would have employed more had they been available. This is a serious problem for employers given the cost of interviews and staff retention issues (GCA, 2015, p. 5).

The Australian Commonwealth Department of Education Science and Training (DEST, 2002) definition of employability skills which was used in this research encompasses the skills not only to gain employment, but also to progress within an enterprise (DEST, 2002, p. 143). This includes technical or discipline specific skills, knowledge, capabilities and personal attributes. More recently, the Australian Employability Skills Framework (2012) specified that ES are those skills and knowledge that enable employees to perform effectively in the workforce and apply technical or discipline specific skills: these are considered context dependent. Typically the views of employers (GCA, 2015) or students are sought in an attempt to ascertain those ES which should be included in curricula (Jackson, 2013; Nilsson, 2010). The views of recent graduates and academics have been reported (Oliver, Whelan, Hunt, \& Hammer, 2011; Gedye, Fender, \& Chalkey, 2004; Crebert, Bates, Bell, Patrick, \& Cragnolini, 2004). Other sources of information include capability lists published by professional colleges (ACHSM, 2014) and the analysis of essential skills identified in vacancy advertisements (Messum, Wilkes, \& Jackson, 2015; Harper, 2012; Varje, Turtianen, \& Vaananen, 2013). However, skills to gain a job appear to be different from those required once a job is secured (Semeijn, Veldon, Heijke, \& Vlueten, 2006; Messum, Wilkes, \& Jackson, 2015). Bennett (2002) found that job advertisements aptly represent the skills and qualities that employers are looking for because the skills listed in the advertisements are carefully chosen to suit the position. It is argued that analysis of relevant job advertisements for current industry skill requirements may provide important information to inform curriculum development and may be useful for current or prospective students. This paper provides an integrative review (Whittemore \& Knafl, 2005) of studies using job advertisements to identify skill requirements across a range of professions.

\section{Research method}

A literature search, (see Messum, Wilkes, \& Jackson, 2011) of peer reviewed publications analysing vacancy advertisements for graduate ES was conducted. Electronic searches used Google Scholar to find peer reviewed articles and references lists were scrutinised. The search was limited to English full text articles, from 1997 through to 2015. Key search words included: ES, competencies, capabilities, job, recruitment or vacancy advertisements, job audit, generic skills, soft skills and content analysis. Search alerts were set up to capture recent publications. In the process of updating the original literature search, 54 articles were found. However after duplicates were removed, 48 remained. These were screened to determine whether author(s) had conducted similar studies and only the most recent articles or those which used a different methodology were selected. This excluded another eight, leaving 41 full text articles. Lastly, a review article was removed (Harper, 2012). A summary of the research strategy is shown in Figure 1.

Messum, D., Wilkes, L., Peters, K., \& Jackson, D. (2016). Content analysis of vacancy advertisements for employability skills: Challenges and opportunities for informing curriculum development. Journal of Teaching and Learning for Graduate 


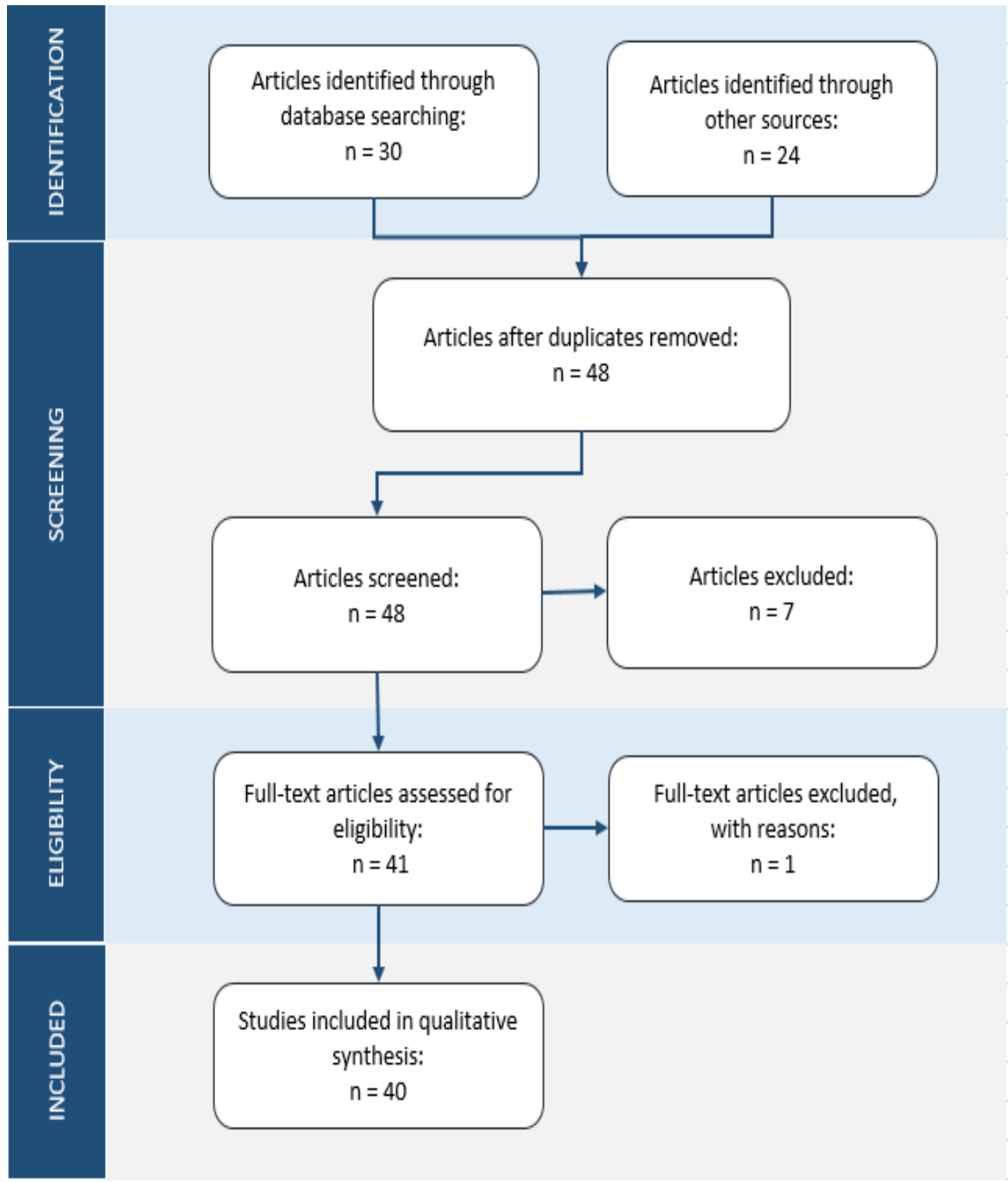

\section{Figure 1: PRISMA 2009 Flow Diagram for Research Method}

To critique the papers, the qualitative checklist of ten questions from the Critical Appraisal Skills Programme (CASP) from the UK National Health Service (2014) was applied. The first three questions relate to clarity of the goal statement, appropriateness of qualitative method and justification of the research design. The data generated included: authors, country where the research occurred, year and journal of publication, and goal statements, (Table 1). Further CASP questions relate to the research method, namely the recruitment strategy; clarity of data collection procedures; whether the researcher examined their own role and potential biases; rigour of the data analysis (e.g. how themes were derived), sampling method and sample size; clarity of findings and consideration of limitations; and value of the research (Tables 2-5). The CASP question about ethics approval and consent is not relevant because data from advertisements is available in the public domain.

\section{Results}

Studies analysing advertisements for ES from 1997 to 2015 were conducted in the UK, USA, Europe, Japan, Malaysia, Australia and New Zealand. All except three studies were published in profession-specific journals, for example various management journals, marketing, social work, advertising, information technology (IT), medicine, leisure and librarianship. None were found in journals relating to higher education and only two were retrieved from a human resources journal. One recent study was found on an employment website. This is consistent with the context specific nature of ES recognised by DEWR (2012). However, it means that exposure to the process and findings from content analysis of job advertisements, is limited.

Messum, D., Wilkes, L., Peters, K., \& Jackson, D. (2016). Content analysis of vacancy advertisements for employability skills: Challenges and opportunities for informing curriculum development. Journal of Teaching and Learning for Graduate 


\section{Table 1: Publication Details and Study Intent}

No Author, year, country and journal

1. Redman \& Mathews (1997), UK. Public Personnel Management

2. Communal \& Senior (1999), Britain, France, Germany. Management Leadership \& Organisational Development Journal.

3. Hawkins et al. (2000), Australia. Australian. Social Work

4. Bennett (2002), London, UK. Journal Vocational Education and Training

5. Arcodia \& Barker (2003), US. Journal Human Resources in Hospitality \& Tourism

\section{Goal statement and industry}

Recruiters requirements for public and private sector marketing and HRM managers

To identify if any differences and similarities in the characteristics required of managers can be explained by reference to the impact of culture.

Sought insight into advertised employment opportunities for social workers.

To identify personal skills required in marketing, finance, general management and HRM.

To classify event management competencies, number of jobs available and track changes for course evaluation.

6. Pember (2003), Australia. Australian. Academic \& Research Libraries.

Knowledge and skills sought by employers for record keeping jobs.

Incidence of personality traits describing the ideal corporate employee.

To identify sectoral differences in management cultures in Ireland.

Organization Development Journal

9. Johnson \& Zlotnik (2005), USA. Mentoring and Tutoring: Partnerships in Learning

Use of mentoring as an ES for psychology academics.

10. Chao \& Shih (2005), USA. IT, Learning, and Performance Journal

Types of Information systems (IS) jobs in demand.

11. Kennan, Willard \& Wilson (2006), Australia. Australian Academic \& Research Libraries

To monitor trends in ES requirements for librarians.

12. Mar Molinero \& Xie (2007), UK. Journal of the Operational Research Society

Skills employers want for operational research, job tasks and employment conditions.

13. Den Hartog, Caley, \& Dewe (2007), UK. Human How do organisations find leaders? To what Resource Management Journal extent is the 'vocabulary of leadership' used.

14. Marchal, Mellet, \& Rieucau (2007), France and Do online vacancy search engines connect or UK. Human Relations

select for jobs as sales managers \& engineers?

15. Orme et al. (2008), UK. Library Review

Employers' requirements for library and information (LIS) professionals.

16. Kennan et al. (2009), Australia. Australasian Journal of Information Systems

Knowledge, skills and competencies demanded of early career IS graduates.

17. Massey (2010), USA. Journalism and Mass Communication Educator

Skills demand for multi-platform reporters. I.e. print, broadcast, the Web, and mobile devices.

18. Sodhi \& Son (2010), USA. Journal of Operational To identify important ES and trends over time in Research operational research skills jobs.

19. Wellman (2010), Wales, UK. Marketing Intelligence and Planning

20. France (2010), NZ, Australia. Journal of Business Ideas and Trends
To inform curriculum development in marketing.

To identify differences between advertised expectations and pedagogy for management accountants.

Messum, D., Wilkes, L., Peters, K., \& Jackson, D. (2016). Content analysis of vacancy advertisements for employability skills: Challenges and opportunities for informing curriculum development. Journal of Teaching and Learning for Graduate 
21. Askehave (2010), Denmark. Journal of Business To analyse the way language is used to construct Communication the ideal bank manager applicant.

22. Messum, Wilkes, \& Jackson (2011), Australia. Asia Pacific Journal of Health Management

To identify current ES required of health managers and update course curriculum.

23. Wise, Henninger, \& Kennon (2011), Australia. Australian Academic and Research Libraries.

24. Emery, Crabtree, \& Kerr (2012), Australia. Annals of Leisure Research

To review and renew curricula for LIS. To identify skills in demand and decline.

Nature and diversity of employment required skill sets in sports management.

25. Ahmed, Capritz, Bouktif, \& Campbell (2012), US, To find out whether employers' soft skills Europe, Asia and Australia. Journal of Systems and Information Technology requirements for different roles of software development, are similar across cultures.

26. Reeves \& Hahn (2012), USA. Journal Education To provide information on skill requirements for Library \& Information Science recent graduates, to update LIS curriculum.

27. Omar, Manaf, Mohd, Kassim, \& Aziz (2012), Malaysia. Asian Social Science

Are graduates employable based on the current pattern of job demands?

28. Chipulu, Neoh, Ojiako, \& Williams (2012). UK, USA, Canada, China, India, HK, Malaysia, Singapore. IEEE Transactions on Engineering Management

29. Quinn \& Rochford (2013), Ireland. Accountancy Role and characteristics required of management Ireland

30. Salleh et al. (2013), Malaysia. International Business Research

To explore key competencies for project managers, across multiple industries. accountants.

To explore and profile architecture industryrelevant competencies.

31. Kuokkanen, Varje, \& Vaananen (2013), Finland. To identify the ideal non-managerial employee. Acta Sociologica

32. Ahsan, Ho, \& Khan (2013), NZ and Australia. Project Management Journal

To compare frequently advertised competencies for project managers by country and industries.

33. Cramer \& Tenzek (2013), USA. Journal of Health To uncover trends in credentials and Care Chaplaincy responsibilities expected of hospice chaplains.

34. Varje, Turtiainen, \& Vaananen (2013), Finland. To analyse the changing representations of the Journal of Management History ideal manager, 1949 to 2009.

35. Rear (2013), Japan and UK. Asian Business and Identify changing work practices based on skills Management required in Japan and UK for IT, IS, engineering, manufacturing, banking, finance and retail.

36. Lavy \& Yadin (2013), Israel. International Journal To map soft skills requirements in IT. of e-Education, e-Business, eManagement and e-Learning

37. Broome \& Gillen (2014), Australia. British Journal To identify competencies required in highof Occupational Therapy. demand areas of OT practice and compare with curriculum.

38. Harris (2014), Canada. Workopolis website

To determine the most in-demand skills by Canadian employers for all jobs, compared with posted resumes on the same website

39. Hong (2015), USA. Journal of Geography

To identify skill requirements of geographic information systems positions

40. Ooi \& Ting (2015), Malaysia. The English Teacher

To examine the emphasis placed on technical and soft skills in job advertisements.

Messum, D., Wilkes, L., Peters, K., \& Jackson, D. (2016). Content analysis of vacancy advertisements for employability skills: Challenges and opportunities for informing curriculum development. Journal of Teaching and Learning for Graduate 


\section{Study intent}

The goals of the studies varied little. Generally they focused on providing insight into employment opportunities, namely types of jobs available and the skill sets, knowledge and competency requirements of industry, the relevant tasks and the diverse nature of a profession. Some compared competency requirements across countries/cultures (Communal \& Senior, 2004; Ahsan, Ho, \& Khan, 2013; Rear, 2013) or revealed institutional differences such as private versus public (Cullen, 2003; Redman \& Mathews, 1997). All of the studies were based on a broad definition of ES, consistent with the DEST (2002) definition encompassing technical or discipline specific skills, knowledge, capabilities and personal attributes. Only one examined generic or 'soft' skills alone (Lavy \& Yadin, 2013). Three focused on specific skills or requirements: the importance of personal skills, a UK government priority in response to employer criticism of graduates, (Bennett, 2002); and the language employers used to describe leadership (Communal \& Senior, 1999; Den Hartog, Caley, \& Dewe, 2007). The importance of experience as an essential job requirement was also identified (Salleh, Yusoff, Amat, Noor, \& Suredah 2013).

Research was conducted to highlight not only current skills requirements, but also skills in demand or decline (Quinn \& Rochford, 2014). Findings from analysing trends over time for particular professions were reported in accounting (France, 2010; Omar, Manaf, Mohd, Kassim, \& Aziz, 2012) and librarianship (Kennan, Willard, \& Wilson, 2006). Others undertook periodic analyses to understand skill changes and trends (Sodhi \& Son, 2010; Cramer \& Tenzek, 2013;) with the intention of keeping skill requirements up to date (Wise, Henninger, \& Kennon, 2011) or determining what skill sets preserve employability in rapidly changing and often global fields (Kennan, Cecez-Kecmanovic, Willard, \& Wilson, 2009). More recently studies have focused on identifying high-demand areas of practice within professions (Wise et al., 2011; Broome \& Gillen, 2014). In Canada, Workopolis (2014) provided the most indemand skills by employers across all job types, and compared the contents of online job postings with the available skills of candidates on the market to identify skill gaps. The Finns have sought to find a country's ideal employee across all jobs, analysing national newspaper advertisements, making comparisons over the last three decades (Kuokkanen, Varje, \& Vaananen, 2013). They have also profiled the ideal manager using the same data sources (Varje, Turtiainen, \& Vaananen, 2013).

Few studies sought information for the purpose of evaluating and renewing teaching and informing curriculum development (Wellman, 2010; Messum et al., 2011; Reeves \& Hahn, 2012; Broome \& Gillen, 2014). These studies explored the skills employers seek in recent graduates and the tasks they are expected to perform on the job. It was argued that although national competency sets exist for many professions, employer requirements may be different and present more up to date skill requirements useful for curriculum renewal (Broome \& Gillen, 2014). Even if this was not the original intention, findings from other studies noted the implications for curriculum development (Lavy \& Yadin, 2013; Emery, Crabtree, \& Kerr, 2012; France, 2010; Kennan et al., 2009; Arcodia \& Barker, 2003). Certainly employers have seen value in listing frequently used competencies to attract potential employees as opposed to using competencies described in the literature and from professional bodies (Reeves \& Hahn, 2012; Cramer \& Tenzek, 2013).

\section{Data}

\section{Data sources}

Table 2 summarises data sources and shows that nearly half the studies used online job recruitment sites and very few used professional publications, or employer websites. More recently, web based sites appear to be the major source of job vacancies. From one (Omar et al., 2012) to as many as 13 online sites were used (Emery et al., 2012). Print media was less

Messum, D., Wilkes, L., Peters, K., \& Jackson, D. (2016). Content analysis of vacancy advertisements for employability skills: Challenges and opportunities for informing curriculum development. Journal of Teaching and Learning for Graduate 
frequently used unless historical trends were being researched as in Finland (Varje et al., 2013).

\section{Table 2: Data Sources}

\begin{tabular}{lrrl} 
Data sources & N & $\%$ & Article number in Table 1 \\
On line recruitment sites & 19 & 47.5 & $4,5,10,16,18,19,20,23-30,32,35,38,39$ \\
\hline Major newspapers & 11 & 27.5 & $2,3,6,7,8,11,13,31,34,36,37$ \\
\hline Professional publications & 4 & 10.0 & $1,9,12,15$ \\
\hline Employer corporate website & 1 & 2.5 & 21 \\
\hline More than one of the above & 5 & 12.5 & $14,17,22,33,40$ \\
\hline
\end{tabular}

$\mathrm{N}=$ number

\section{Sample size and sampling procedure}

Table 3 reports the number of advertisements reviewed and sampling procedures. Sampling was purposive whether determined by source, for example, certain newspapers or online job sites, time period, place (e.g. a country), profession(s), sector of employment, or type of ES or experience requirements. All studies removed duplicates. Some set a target number of advertisements for collection, for example, 100, a time period such as three months, or sampled within a time period, for instance the first Saturday of the month, one week every three months or every third advertisement, typically to remove seasonal variations. A few used a random number generator when numbers were large to avoid bias in selection of advertisements for analysis. Sample size varied from only one advertisement used in multiple locations across a country to over 3000. Over 40 per cent collected 500 advertisements or more and 22 per cent collected over 1000 . Only four collected under 100, while for two studies sample size was not stated (Cremin, 2005; Harris, 2014). Use of large samples may be explained by the more recent ready availability of data from online job sites.

\section{Table 3: Data Sampling and Number of Advertisements Analysed}

\begin{tabular}{lcrl} 
Data sampling and size & $N$ & $\%$ & Article number in Table 1 \\
Random sample: & 5 & 12.5 & \\
$<100$ ads & 0 & 0 & \\
$100-499$ ads & 4 & 10.0 & $1,15,25,35$ \\
$>500$ ads & 1 & 2.5 & 4 \\
NS & 0 & 0 & \\
\hline Purposive sample: & 20 & 50.0 & \\
$<100$ ads & 2 & 5.0 & 21,33 \\
$100-499$ ads & 10 & 25.0 & $2,8,10,11,17,20,23,26,35,40$ \\
$>500$ ads & 7 & 17.5 & $12,14,26,32,34,36,39$, \\
NS & 1 & 2.5 & 7 \\
& & & \\
\hline Census over set time period: & 15 & 37.5 & \\
$<100$ ads & 2 & 5.0 & 6,30 \\
$100-499$ ads & 5 & 12.5 & $5,16,22,27,29$, \\
$>500$ ads & 7 & 17.5 & $3,9,13,18,24,28,37$ \\
NS & 1 & 2.5 & 38
\end{tabular}


Manual data analysis was used in the majority of studies to count the most frequently occurring skills required as shown in Table 4. Five more recent studies used NVivo, Provalis Simstat, Leximancer or Wordstat. Cross tabulations were performed for comparison purposes in seven studies. Statistical software programs were applied to the derived data in a quarter of studies only, which had large enough sample sizes. Few used a predetermined coding frame to categorise data into themes.

Table 4: Data Coding and Analysis

\begin{tabular}{|c|c|c|c|}
\hline Data coding and analysis & $\mathrm{N}$ & $\%$ & Article number in Table 1 \\
\hline Manual frequency counts of all key words & 16 & 40 & $3,5,6,8,10,12,14,15,20,22,25,29-31,40$ \\
\hline Manual tally using pre-set codes & 10 & 25 & $1,2,18,19,24,26,27,32-34$ \\
\hline Manual tally selected key words only & 4 & 10 & $7,9,23,36$ \\
\hline $\begin{array}{l}\text { Mixed methods e.g. word counting } \\
\text { software applied, or manual coding then } \\
\text { proximal plots or cluster analysis }\end{array}$ & 10 & 25 & $4,11,13,16,17,21,28,35,37-39$ \\
\hline
\end{tabular}

$\mathrm{N}=$ number *More than one item could have been used

Study rigour and control of bias was not well addressed in most studies. Only six discussed any pilot study to develop a coding frame, and five checked coder reliability. Three followed up findings with focus groups or surveys to verify findings, for example to find out why skills were listed by managers (Bennett, 2002) or to clarify the meaning of a term such as leadership (France, 2010; Messum et al., 2011). Acknowledgement of study limitations was found in one third of studies only. Ten noted the need for follow up and triangulation with employers, recent employees or job applicants to corroborate findings, and/or the need for a larger sample or longer time period to collect data. Five mentioned limited external validity, due to incomplete coverage or non-inclusion bias such as internal hiring, use of only one data source, or findings from one country only. Coding problems due to ambiguity in interpretation and the lack of shared understanding of the terms used occurred in five studies. One study noted that the ES identified may not reflect actual hiring decisions (Cramer \& Tenzek, 2013), or the job demands once hired (Massey, 2010).

\section{Most commonly identified ES}

Table 5 reveals that communication skills were the most commonly advertised skill requirement followed by teamwork, job specific skills and experience. However, communication skills were also variously identified as social skills (Redman \& Mathews, 1997) and interpersonal skills (Wise et al., 2011) or listed as an item in a cluster of skills. Other studies viewed communication skills as a distinct skill separate from interpersonal skills (Den Hartog et al., 2007; Omar et al., 2012; Hong, 2015; Salleh et al., 2013). Rear (2013) concluded that communication skills mean different things in different countries. Six studies did not report specific ES, or focused on one ES only, for example leadership. 
Table 5: Rank Order of ES found in Advertisements*

\begin{tabular}{|c|c|c|c|}
\hline Findings & N & $\%$ & Article number in Table 1 \\
\hline Communication skills & 25 & 62.5 & $1,4-8,10,12,13,15,18,19,22-27,30-32,35,36,38-40$ \\
\hline Teamwork & 13 & 32.5 & $4,6,15,18,19,22,26,27,30,36-38,40$ \\
\hline Job specific or technical skills & 10 & 25.0 & $6,12,16,18-20,31,32,37,39$ \\
\hline Experience & 10 & 25.0 & $3,6,10,15,16,19,22,24,26,28$ \\
\hline Interpersonal skills & 9 & 22.5 & $2,6,11,13,15,23,30,35,39$ \\
\hline Organisational skills, planning & 7 & 17.5 & $4,5,8,19,24,38,40$ \\
\hline IT, computing, software skills ${ }^{* *}$ & 7 & 17.5 & $4,6,12,19,22,27,38$ \\
\hline Tertiary qualifications & 7 & 17.0 & $3,15,16,18,22,31,37$ \\
\hline Leadership & 3 & 7.5 & $8,18,29$ \\
\hline Personal qualities & 3 & 7.5 & $1,27,34$ \\
\hline Creativity and innovation & 3 & 7.5 & $1,19,25$ \\
\hline Analytical skills & 3 & 7.5 & $8,18,22$ \\
\hline Problem solving & 2 & 5.0 & 12,38 \\
\hline Project management & 2 & 5.0 & 8,18 \\
\hline Work independently & 2 & 5.0 & 20,40 \\
\hline $\begin{array}{l}\text { Other eg good fit, commitment, } \\
\text { drive change, ethical, service } \\
\text { orientation, LLL, time } \\
\text { management, collaboration } \\
\text { skills }\end{array}$ & 6 & 15.0 & $23,25,26,35,36,38$ \\
\hline
\end{tabular}

$\mathrm{N}=$ Number *More than one could be reported. ** IT skills for IT industry are listed as job specific skills.

\section{Value of the research}

Various claims about the value of the research were provided. Several confirmed that generic skills were as, or more important, than discipline specific skills to secure a job, (Chipulu, Neoh, Udechukwu, \& Williams, 2012; Varje et al., 2013; Lavy \& Yadin, 2013; Broom \& Gillen, 2014). Longitudinal studies showed changing skill requirements over time with increased emphasis on soft skills rather than job or profession-specific skills (Hawkins et al., 2000; Quinn \& Rochford, 2013; Cramer \& Tenzek, 2014). Monitoring of market trends to define current skill requirements was well supported although cultural and other contextual differences were acknowledged, (Cullen 2003; Den Hartog et al., 2007; Ahmed, Capritz, Bouktif, \& Campbell 2012; Reeves \& Hahn, 2012; Kuokkanen et al., 2013; Ahsan et al., 2013). In fact one third (13) of the studies specifically recommended that HEI should use their findings for academic advising, updating curriculum and to help new graduates align with skill requirements of industry. They argued that HEI should teach generic skills required by industry: in particular communication skills and teamwork should be addressed. One study revealed a poor match between curriculum and professional competency lists (France 2010). Three studies saw value in current employees, employers, human resources managers or graduates using their findings (Ahsan et al., 2012; Ahmed et al., 2012; Messum et al., 2011). The importance of work experience was also confirmed and taken to support the importance of work integrated learning and industry placements, (Messum et al., 2011). The value of using content analysis of advertisements as a supplement to employer interviews to identify job requirements was also confirmed (Reeves \& Hahn, 2012; Emery et al.,2012).

Messum, D., Wilkes, L., Peters, K., \& Jackson, D. (2016). Content analysis of vacancy advertisements for employability skills: Challenges and opportunities for informing curriculum development. Journal of Teaching and Learning for Graduate 


\section{Discussion}

Content analysis of job advertisements has been widely used by various professions to identify commonly required ES and trends in skill requirements. However, relatively few studies were found in many different refereed journals. This may explain why content analysis of vacancy advertisements is not frequently used to triangulate ES research. It appears to be a worthwhile alternative or adjunct to employer surveys, with the advantages of currency, accessibility and low cost. Researchers even argued that results from their research challenged professional competency sets and found current curriculum wanting, (France 2010; Messum et al., 2011; Broome \& Gillen, 2014). One third of the studies recommended that findings be used to inform curriculum development. Furthermore, additional uses to required skills lists were revealed in this integrative review. For example, Askehave (2010) found advertisements attracted male rather than female applicants, when the potential employment pool of females was the larger. Furthermore, the wording of their advertisement restricted rather than attracted applicants: feedback useful to human resources departments. Regular monitoring of advertisements can identify trends in ES requirements, areas of high demand within a profession, and where jobs are located, which is useful information for recent graduates and careers advisors.

There were consistent findings emphasising the importance of generic skills such as communication skills and teamwork. Furthermore, such skills have remained important over time as shown from longitudinal analysis of ES trends in advertisements, (Varje et al., 2013). Massey (2010), concluded that skill sets are in transition, with a move towards generic skills rather than job or profession-specific skills (Hawkins et al., 2000; Cramer \& Tenzek, 2014; Quinn \& Rochford, 2013). These skills may well protect and preserve employability. For example, the ES that are required to secure a job as found in vacancy advertisements have been found to be somewhat different skill sets to those that help employees progress in the employing organisation (Semeijn et al., 2006; Messum et al., 2015)). The skills for successful long term employment need to be studied. However, definition of individual ES is not agreed. For example, this review revealed that communication skills mean different things to different researchers. In depth studies exploring words like personal attributes, leadership and soft skills, included in this review, help to clarify understanding. Use of agreed definitions on webbased job vacancy sites is also recommended.

The ES profiles that emerged varied not only by industry and discipline, but also by country or culture (Marchal, Mellet, \& Rieucau, 2007; Communal \& Senior, 1999; Quinn \& Rochford, 2013; Rear, 2013; Ahmed et al., 2013; Cramer \& Tenzek, 2014). Our review supports the conclusion of DEWR (2012) that ES are context specific. It means that lists of ES for school leavers or university wide graduate attributes may not be enough to help students identify skill requirements for their chosen profession. Listing of the most frequently required ES is a start, but their importance for various professions has been found to vary, plus discipline specific skills or technical skills and experience requirements need to be known. The recommendation from this review is that researchers need to use a broad definition of ES such as that offered by DEWR, and identify current, context specific ES. Although GCA (2015) provides annual updates on the most common ES required by industry, there is still a need to disaggregate data by discipline.

According to the literature, another important, if not the most important ES requirement, was experience (Orme, 2008). This review found one quarter of advertisements required experience. Chao and Shih (2005) found experience was listed in 67 per cent of advertisements, Wellman (2010) reported 52 per cent and Kennan et al., (2009) 50 per cent. Some studies found that it was even a requirement for new entry positions (Messum et al., 2011; Reeves \& Hahn, 2012; Chipulu et al., 2013). This finding may help explain recruitment shortages identified by GCA (2015), and has important implications for $\mathrm{HEl}$ and work integrated learning, as well as employers. The wording used in advertisements may deter applicants if experience is emphasised or narrowly defined.

Messum, D., Wilkes, L., Peters, K., \& Jackson, D. (2016). Content analysis of vacancy advertisements for employability skills: Challenges and opportunities for informing curriculum development. Journal of Teaching and Learning for Graduate 
There is a need to improve rigour in content analysis studies of advertisements. Some authors used a predetermined coding frame to categorise data into themes, but problems were noted about agreement of coders. The majority of studies allowed their coding frames to be data driven, tallying the advertised skill requirements to identify themes. Sodhi and Son (2010) argued that manual analysis is superior to computerised analysis in terms of accuracy of frequency counts, because words have different meanings in different contexts. However, this review found that few used pilot studies or cross checked coder reliability.

More recently, web based job sites appear to be the major source of advertisements. However, Marchal et al. (2007) argued that online job advertisements constrain employers by requiring use of pre-defined lists, keywords and input fields, making entries more standardised and quantified than newspaper advertisements. Similarly they found that search engine toolkits restrict wording used to find job skill requirements. Yet the opportunity is there for job sites to clearly define commonly used terms and overcome this problem.

\section{Recommendations for further research}

A mixed methods approach of content analysis followed up with employers and or recent graduates would be useful to verify findings. Then the extent to which selection criteria attracts suitable applicants can be investigated. This would help provide external validity for criteria used in job advertisements. However, the process of content analysis of job advertisements must be improved with larger data sets from online sites, and better measures to ensure reliability. Furthermore, researchers need to report both the frequency of occurrence of common ES, as well as the composition of clusters that emerge from more sophisticated data analysis. These serve different purposes: the first identifies commonly required ES across many jobs; the latter describes specific skill sets for professions and industries. This moves content analysis research beyond descriptive frequency counts to more useful information. It is also important that common definitions of terms be agreed, which more in depth study of particular ES may reveal. On line job sites could then provide definitions of ES based on the evidence.

\section{Conclusion}

Triangulation efforts for curriculum development have included not only employers, but also recent graduates, applicants for positions, professional bodies and recruitment agencies. Given the limitations of stakeholder lists of ES an objective, additional or alternative sources of information to at least corroborate views, is needed. The advantages of analysing advertisements for ES include: ready accessibility, potentially large data sets, at low cost and not always time consuming method to determine those ES required on the job. As a qualitative exercise it can provide a wealth of useful information to inform curriculum development, careers advisors, current students and graduates about the ES employers require in specific fields. However, the challenge is to improve external validity, sampling techniques, sample sizes and agree common definition of terms when using content analysis. Allowing the data to drive findings rather than forcing ES identified in advertisements into pre-determined categories is also recommended. 


\section{References}

ACHSM. (2014). Health Management Internship Program (NSW) Emerging Manager Competency Framework. N. Ryde: ACHSM.

Arcodia, C. \& Barker, T. (2003). The employability prospects of graduates in event management: Using data from job advertisements. Journal of Human Resources in Hospitality \& Tourism, 1:4, 1-18.

Ahmed, F., Capritz, L.F., Bouktif S., \& Campbell, P. (2012). Soft skills requirements in software development jobs: A cross-cultural empirical study. Journal of Systems and Information Technology, 14(1), 58-81.

Ahsan, K., Ho, M., \& Khan, S. (2013). Recruiting project managers: A comparative analysis of competencies and recruitment signals from job advertisements. Project Management Journal, 44(5), 36-54.

Archer, W. \& Davidson, J. (2008). Graduate employability: What do employers think and want? London: The Council for Industry and Higher Education (CIHE).

Askehave, I. (2010). Communicating leadership: A discourse analytical perspective on the job advertisement. Journal of Business Communication, 47(3), 313-45.

Bennett, R. (2002). Employers' demands for personal transferable skills in graduates: A content analysis of 1000 job advertisements and an associated empirical study. Journal of Vocational Education and Training, 54(4), 457-75.

Broome, K. \& Gillen, A. (2014) Implications of occupational therapy job advertisement trends for occupational therapy education. The British Journal of Occupational Therapy, 77(11), 574-581.

Chao, C. \& Shih, S.C. (2007). Organizational and end-user information systems job market: An analysis of job types and skill requirements. Information Technology, Learning, and Performance Journal, 23(2), 1-15.

Chipulu, M., Neoh, J.G., Udechukwu, O., \& Williams, T. (2012). A multidimensional analysis of project manager competencies. IEEE Transactions on Engineering Management, 60(3). Available: 10.1109/TEM.2012.2215330

Cramer, E.M. \& Tenzek, K. (2012). The chaplain profession from the employer perspective: An analysis of hospice chaplain job advertisements. Journal of Health Care Chaplaincy, 18(3-4), 133-150.

CBI Changing the Pace. 2013. Available: http://www.cbi.org.uk/media/2119176/education_and_skills_survey_2013.pdf

Crebert, G., Bates, M., Bell, B., Patrick, C., \& Cragnolini, V. (2004). Developing generic skills at university, during work placements and in employment: Graduates' perceptions. Higher Education Research and Development, 23(2), 147-64.

Cremin, C.S. (2003). Self-starters, can-doers and mobile phoneys: Situations vacant columns and the personality culture in employment. Sociological Review, 51, 109-28.

Critical Appraisal Skills Programme (2014). CASP Qualitative checklist, Oxford. Available under Creative Commons Licence: http://www.casp-uk.net/untitled).

Communal, C. \& Senior, B. (1999). National culture and management: Messages conveyed by British, French and German advertisement for managerial appointments. Leadership and Organization Development Journal, 20(4), 26-35.

Commission for Employment and Skills. National Employers Survey 2013: UK Results. Available:

https://www.gov.uk/government/uploads/system/uploads/attachment_data/file/327492/ev idence-report-81-ukces-employer-skills-survey-13-full-report-final.pdf

Cullen, J. (2003). Identifying sectoral management cultures through recruitment advertising. Leadership \& Organization Development Journal, 25(3), 279 -291.

Messum, D., Wilkes, L., Peters, K., \& Jackson, D. (2016). Content analysis of vacancy advertisements for employability skills: Challenges and opportunities for informing curriculum development. Journal of Teaching and Learning for Graduate 
Den Hartog, D.N., Caley, A., \& Dewe, P. (2007). Recruiting leaders: An analysis of leadership advertisements. Human Resource Management Journal, 17, 58-75.

Department of Education, Science and Training (DEST) (2002). Employability skills for the future. A report by the Australian Chamber of Commerce and Industry and the Business Council of Australia for DEST. Canberra: DEST.

Emery, P.R., Crabtree, R.M., \& Kerr, A. K. (2012). The Australian sport management job market: An advertisement audit of employer need. Annals of Leisure Research, 15(4), 335-353.

Ferns, S. \& Lilly, L. (2015). Driving institutional engagement in WIL: Enhancing graduate employability. Journal of Teaching and Learning for Graduate Employability, 6(1), 116133.

France, A. (2010). Management accounting practices reflected in job advertisements. Journal of Business Ideas and Trends, 8(2), 41-57.

Gedye, S., Fender, E., \& Chalkey, B. (2004). Students' undergraduate expectations and postgraduate experiences of the value of a degree. Journal Geography in Higher Education, 28(3), 381-96.

Graduate Careers Australia (GCA). (2015). The Report of the Graduate Outlook Survey: Employers' Perspectives on Graduate Recruitment, 2015, p.8. Available: http://www.graduatecareers.com.au/research/surveys/graduateoutlooksurvey/

Harper, R. (2012). The collection and analysis of job advertisements: A review of research methodology. Library and Information Research, 36(112), 29-54.

Hawkins, L., Ryan, M., Murray, H., Grace, M., Hawkins, G., Mendes, P., \& Chatley, B. (2000). Supply and demand: A study of labour market trends and the employment of new social work graduates in Victoria. Australian Social Work, 53(1) 35-42.

Hinchliffe, G.W. \& Jolly, A. (2011). Graduate identity and employability. British Education Research Journal, 37(4), 563-84.

Hong, J.E. (2015). Identifying skill requirements for GIS positions: A content analysis of job advertisements. Journal of Geography, 115(4), 147-58.

Jackson, D. (2013). Student perceptions of the importance of skill provision in business undergraduate programs. Journal of Education for Business, 88(5), 271-279.

Johnson, B.W. \& Zlotnik, S. (2005). The frequency of advising and mentoring as salient work roles in academic job advertisements Mentoring and Tutoring: Partnerships in Learning, 13(1), 95-107.

Kennan, M.A., Willard, P., \& Wilson C.S. (2006). What do they want? A study of changing employer expectations of information professionals. Australian Academic and Research Libraries, 37(1), 17-37.

Kennan, M.A., Cecez-Kecmanovic, D., Willard, P., \& Wilson, C.S. (2009). IS knowledge and skills sought by employers: Content analysis of Australian IS early career job advertisements. Australasian Journal of Information Systems, 15(2), 169-190.

Kuokkanen, A., Varje, P., \& Vaananen, A. (2013). Transformation of the ideal Finnish employee ideal in job advertisements from 1944 to 2009. Acta Sociologica, 56(3), 213226.

Lavy, I. \& Yadin, A. (2013). Soft skills - An important key for employability in the "shift to a service driven economy" era. International Journal of e-Education, e-Business, eManagement and e-Learning, 3(5), 416-420.

Liang, Z., Short, S.D., \& Brown, C.R. (2006). Senior health managers in the new era: Changing roles and competencies in the 1990 s and the early 21 st century. Journal Health Administration Education, Summer, 81-301.

Messum, D., Wilkes, L., Peters, K., \& Jackson, D. (2016). Content analysis of vacancy advertisements for employability skills: Challenges and opportunities for informing curriculum development. Journal of Teaching and Learning for Graduate 
Marchal, E. Mellet, K., \& Rieucau, G. (2007). Job board toolkits: Internet matchmaking and changes in job advertisements. Human Relations, 60, 1009-1113.

Massey, B.L. (2010). What job advertisements tell us about demand for multi-platform reporters of legacy news outlets. Journalism and Mass Communication Educator, 65(2), 142-155.

Messum, D., Wilkes, L., \& Jackson, D. (2011). Employability skills: Essential requirements in health manager vacancy advertisements. Asia Pacific Journal of Health Management, 6, 22-28.

Messum, D., Wilkes, L., \& Jackson, D. (2015). What employability skills are required of new health managers? Asia Pacific Journal of Health Management, 10, 28-35.

Mar Molinero, C. \& Xie, A. (2007). What do UK employers want from OR/MS? Journal of the Operational Research Society, 58, 1543-1553.

Nilsson, S. (2010). Enhancing individual employability: The perspectives of engineering graduates. Education + Training, 52(6/7), 540-551.

Oliver, B., Whelan, B., Hunt, L., \& Hammer, S. (2011). Accounting graduates and the capabilities that count: Perceptions of graduates, employers and accounting academics in four Australian universities. Journal Teaching and Learning for Graduate Employability, 2(1), 2-21.

Omar, N.K., Manaf, A.A., Mohd, R.H., Kassim, A.C., \& Aziz, K. (2012). Graduate employability skills based on current job demand through electronic advertising. Asian Social Science, 8(9), 1103-1110.

Orme, V. (2008). You will be.....A study of job advertisements to determine employers' requirements for LIS professionals in the UK in 2007. Library Review, 57(8), 619-633.

Ooi, K.B. \& Ting, S.H. (2015). Employers' emphasis on technical skills and soft skills in job advertisements. The English Teacher, XLIV (1), 1-12.

Pember, M. (2003). Content analysis of recordkeeping jobs advertisements in Western Australia: Knowledge and skills required by employers. Australian Academic and Research Libraries, 34(3), 194-210.

Precision Consultancy (2007). Graduate Employability Skills. Report Prepared for the Business, Industry and Higher Education Collaboration Council, Australia, August 2007.

Public Health Resource Unit, UK (2016). Critical appraisal skills programme (CASP), making sense of evidence: Qualitative checklist. Available: http://www.casp-uk.net/checklists

Quinn, M. \& Rochford, D. (2013). What management accountants do. Accountancy Ireland, 45(1), 58-60.

Rear, D. (2013). Converging work skills? Job advertisements and generic skills in Japanese and Anglo-Saxon contexts. Asian Business and Management, 12(2), 173-196.

Redman, T. \& Mathews, B.P. (1997). What do recruiters want in a public sector manager? Public Personnel Management, 26(2), 245-56.

Reeves, R.K. \& Hahn, T. (2012) Job advertisements for recent graduates: Advising, curriculum and job seeking implications. Journal Education Library and Information Science, 51(2), 103-119.

Ridoutt, L., Selby Smith, C., Hummel, K., \& Cheang, C. (2005). What value do Australian employers give to qualifications? Adelaide: National Centre for Vocational Education Research (NCVER).

Salleh, R., Yusoff, A., Amat, C.A., Noor, A.M., \& Suredah, N. (2013). Profiling industry relevant competencies of graduate architects through job advertisements. International Business Research, 6(11), 43-51. 
Semeijn, J., Veldon, R., Heijke, H., Vlueten, C., \& Boshuizen, A. (2006). Competence indicators in academic education and early labour market success of graduates in health sciences. Journal of Education and Work, 19(4), 383-413.

Sodhi, M.S. \& Son, B-G. (2010). Content analysis of OR jobs advertisements to infer required skills. Journal of Operational Research, 61, 1315-1327.

Tymon, A. (2011). The student perspective on employability. Studies in Higher Education, 38(6), 841-56. DOI: 10.1080/03075079.2011.604408

Universities Australia. (2014). National WIL Strategy. Available: http://cdn1.acen.edu.au/wpcontent/

Varje, P., Turtiainen, A., \& Vaananen, J. (2013). Psychological management: Changing qualities of the ideal manager in Finland 1949-2009. Journal of Management History, 19(1), 33-54. DOI: http://dx.doi.org/10.1108/17511341311286187

Wellman, N. (2010). The employability characteristics of new marketing graduates. Marketing Intelligence and Planning, 28(7), 908-930.

Whittemore, R. \& Knafl, K. (2005) The integrative review: Updated methodology. Journal Advanced Nursing, 52(5), 546-53.

Wise, S., Henninger, M., \& Kennon, M.A. (2011). Changing trends in LIS job advertisements. Australian Academic and Research Libraries, 42(4), 268-95.

Workopolis (2014). The most sought after skills in Canada Available:

http://hiring.workopolis.com/research/thinkopolis/viii-skills/ 